\title{
O conceito de ideologia na teoria do jornalismo de Adelmo Genro Filho
}

Felipe Simão Pontes

Resumo: Parte-se da exegese ontometodológica de "O Segredo da Pirâmide: para uma teoria marxista do jornalismo" e de outros ensaios de Adelmo Genro Filho para compreender sua concepção de ideologia, procedimento que julgamos incontornável para entender sua definição do jornalismo como forma de conhecimento. Genro Filho trabalha com três atribuições ao termo ideologia: a crítica à ideologia da objetividade jornalística; a crítica às teorias que consideram o jornalismo exclusivamente como aparelho ideológico de classe; e a possibilidade de o jornalismo ser feito para uma ideologia do proletariado. Identificamos que a concepção de ideologia de Genro Filho é similar à de Gyorgy Lukács, manifesta em "O Ideal e a Ideologia", capítulo de "Para uma Ontologia do Ser Social II". A análise proposta permite a discussão do jornalismo como conhecimento e ideologia, o que revela pertinência frente à crise simbólica do jornalismo tradicional.

Palavras-chave: jornalismo; ideologia; conhecimento; Adelmo Genro Filho; Gyorgy Lukács.

Abstract: The concept of ideology in Adelmo Genro Filho's theory of journalism - This paper introduces Adelmo Genro Filho's concept of ideology, as well as his definition of journalism as a form of knowledge, based on an onto-methodological exegesis of his essay The pyramid secret: towards a Marxist theory of journalism. He talks about three attributes to the term ideology: a criticism of the ideology of journalistic objectivity; a criticism of theories considering journalism exclusively as a class ideological device; and the possibility of a journalism made to a proletarian ideology. Genro Filho's concept of ideology comes up to be similar to that of György Lukács, as written in "The ideal and the ideology" (Ontology of social being II). This analysis proposes to discuss the journalism both as knowledge and ideology, which seems suitable to face the symbolic crises of traditional journalism.

Keywords: journalism; ideology; knowledge; Adelmo Genro Filho; Gyorgy Lukács. 
Neste texto, temos o objetivo de reconhecer o conceito de ideologia trabalhado por Genro Filho em "O Segredo da Pirâmide: para uma teoria marxista do jornalismo". O exercício é incontornável para a análise da estrutura teórica constituída para a definição do jornalismo como forma de conhecimento. A tática é expor a exegese do autor frente ao conceito de ideologia disposto na tradição marxista de pensamento; em específico, apontar as proximidades de seu pensamento à concepção de Lukács (2013).

Para isso, revisamos os usos do conceito no livro e em textos anteriores de Genro Filho, reconstituindo o arcabouço ontometodológico no qual seu pensamento se circunscreve e percebendo o conceito no interior da arquitetura teórica proposta, em debate com as fontes de que ele dispunha. Chasin (2009, p. 24) expõe que a análise deve "reproduzir a reflexão pelo interior", ao modo pelo qual o próprio autor a concebeu e expressou.

Procedimento, pois, que adquire articulação e identidade pela condução ininterrupta de uma analítica matizada pelo respeito à estrutura e à lógica inerente ao texto examinado, ou seja, que tem por mérito a sustentação de que antes de interpretar ou criticar é incontornavelmente necessário compreender e fazer prova de haver compreendido.

Tecemos uma comparação da definição de ideologia proposta por Genro Filho e a realizada por Lukács. Genro Filho usou "Introdução à Estética Marxista: sobre a categoria da particularidade" para conceituar o jornalismo, sem o registro de seu contato com a totalidade da "Ontologia do Ser Social", obra de Lukács apenas publicada totalmente no Brasil em 2012 e 2013ํ․ É nesse livro, no capítulo "O Ideal e a Ideologia", que Lukács (2013, p.355-575) discute os "pores teleológicos secundários" ", isto é, como alguns sujeitos desejam convencer (e muitas vezes convencem) outros sujeitos a agirem segundo as finalidades que os primeiros almejam. A ideologia é a modalidade central desse processo de convencimento no âmbito coletivo. Sob este aspecto, indicamos algumas proximidades das concepções de Genro Filho e de Lukács sobre ideologia, bem como algumas consequências do conceito para a proposição do jornalismo como forma de conhecimento.

O "Segredo da Pirâmide", publicado em 1987, propõe uma teoria específica, segundo a qual o jornalismo é uma forma de conhecimento cristalizado no singular [com base em Lukács (1970)]. O livro foi publicado em um contexto em que o jornalismo é concebido pelos acadêmicos e profissionais brasileiros como técnica, como uma forma de integração orgânica e funcional da sociedade ou como manifestação ideológica que deturpa a realidade (concepção ligada à primeira fase da Escola de Frankfurt, à influência

1 Em 1979, Carlos Coutinho traduziu o capítulo "A Falsa e a Autêntica Ontologia de Hegel" e "Os Princípios Ontológicos Fundamentais de Marx". Nos textos de Genro Filho, localizamos apenas a menção ao capítulo "Os Princípios Ontológicos Fundamentais de Marx". Em "O Segredo" não há qualquer menção a essas traduções.

2 O pôr teleológico refere-se à ação do sujeito direcionada a uma finalidade. Essa finalidade é atingida mediante a intervenção laborativa dos homens e mulheres sobre a natureza, relacionando-se com as causalidades existentes. Pôr teleológico e causalidades compõem a concepção ontológica medular de Marx: o trabalho. 
de Althusser e dos pós-estruturalistas). Ao indicar que a notícia é uma forma de conhecimento, Genro Filho reconfigura as concepções dispostas naquele momento no Brasil $^{3}$, inovação que encontra leitores e entusiastas da tese nos últimos 28 anos.

As discussões do jornalismo como forma de conhecimento e das relações do jornalismo com a ideologia são recorrentes no Brasil. Teóricos ou pesquisadores como Gonçalves (1992), Meditsch (1992), Moretzsohn (2007), Sponholz (2008), entre muitos outros, trabalham com a definição de jornalismo como forma de conhecimento em suas relações com a linguagem, o ensino, a ciência e o exercício profissional crítico. Por sua vez, desde os anos 1970, Medina (1978), Lage (1979) e Marcondes Filho (1986) entre muitos outros analisam o jornalismo em sua relação com a ideologia. Os trabalhos de Marshall (2003) e Rüdiger (2010) atualizam o debate, questionando inclusive a viabilidade de o jornalismo ser exercido como conhecimento em tempos de publicidade, espetáculo e da indústria cultural como sistema ordenador da produção cotidiana.

Tendo esse debate por fundo, este texto explora o estudo específico do conceito de ideologia conforme trabalhado por Genro Filho, uma vez que são encontrados equívocos em citações de "O Segredo" ou interpretações que não enfatizam essa questão. Além disso, a compreensão de jornalismo como forma de conhecimento costuma ser considerada frágil ou em colapso em momentos de crise simbólica pelos quais passam os veículos de mídia mais tradicionais. Especificamente, o país atravessa um período de fortes disputas ideológicas, no qual a política editorial dos veículos de comunicação e as notícias tomam parte, pois, inerentemente, essas disputas atravessam a produção de fatos sociais. Nesse sentido, ao recuperar as concepções de Genro Filho sobre ideologia e conhecimento, visamos oferecer explicações sobre o trabalho jornalístico realizado e possível neste contexto.

Pode parecer uma questão epistemológica tratar de ideologia em uma proposta teórica para o jornalismo como a realizada por Genro Filho em "O Segredo da Pirâmide". Essa interpretação decorre da oposição clássica na gnosiologia e na sociologia entre teoria e ideologia, ciência e ideologia ou conhecimento e ideologia ${ }^{4}$. Sob uma vertente epistemológica, o marxismo advoga a ideologia somente como falsa consciência, como uma imagem equivocada do real. A teoria teria por tarefa revelar a "falsidade". A ideologia é caracterizada, nessa modalidade de abordagem, como vinculada à classe dominante que, como classe, detém os meios materiais de exploração e corporifica

3 A proposta do jornalismo (e mais precisamente da notícia) como forma de conhecimento é originalmente manifesta por Park (1940) e influencia muitos estudos em jornalismo, principalmente vinculados ao newsmaking.

4 Entre as publicações sobre a questão, destacamos o paradigmático texto de Mannheim (1972), a análise sobre a história do conceito de Ricouer (1991) e as considerações do conceito para a comunicação de Thompsom (1995). 
o domínio na criação de estruturas ideológicas que asseguram a docilidade dos dominados. Somente a teoria ou a ciência marxista teriam a possibilidade de revelar essa relação, contribuindo como artífices no combate à ideologia.

Por outro lado, correntes não marxistas apontam a não cientificidade do método proposto por Marx justamente por não dissociar a explicação sobre as conexões da realidade do interesse em transformar a realidade. A tarefa do conhecimento no marxismo em denunciar a ideologia dominante é apresentada como um defeito de origem. Ao se propor transformar o mundo, dizem os críticos, o marxismo carrega em si uma ideologia e contamina o fazer da ciência ${ }^{5}$. O marxismo precisaria escolher entre fazer ciência ou ideologia. Como afirma Lukács (2013, p. 567), a crítica gnosiológica restrita não compreende a ideologia e o marxismo. Um estudo ontológico da ideologia busca dirimir tais mal-entendidos.

Nesse aspecto, há proximidades entre as concepções de ideologia em Lukács e as de Genro Filho. O teórico gaúcho também não acredita que a oposição teoria / ciência versus ideologia seja adequada para entender a questão. A sua definição de ideologia está mais desenvolvida no texto em que analisa o livro "O que é Ideologia", de Marilena Chauí. O texto "A Ideologia da Marilena Chauí" traz indicações de que a autora realiza o mesmo movimento de Althusser, colocando poder em demasia nas mãos dos intelectuais e teóricos. Genro Filho aponta que o conceito de ideologia de Chauí advém de um "socialismo de cátedra", como se as questões da realidade pudessem ser resolvidas a partir da proposição de uma teoria. Portanto, "[...] só realizável efetivamente como tese de mestrado ou doutorado. Trata-se de uma vulgar pedagogia, na qual o proletariado entra apenas como cobaia para que "o saber real" demonstre toda sua grandeza" (GENRO FILHO, 1986, p.96).

Por isso, Genro Filho critica a interpretação unilateral da proposição de Marx de denúncia à ideologia apenas como a zona de erro, percebendo a ideologia também como espaço de disputa. Assim como Lênin e Gramsci, Genro Filho julga que contra uma ideologia burguesa é necessária uma ideologia revolucionária. "Dizer que toda ideologia é, necessariamente, um instrumento de dominação significa pensar na luta de classes na forma de uma paródia na qual se enfrentam não o proletariado e a burguesia, mas uma suposta sabedoria teórica [...] e a alienação dos dominados" (GENRO FILHO, 1986, p.97). Ao tecer a crítica ao texto de Chauí, o teórico gaúcho caracteriza grande parte das teorias sobre a ideologia de correntes marxistas e de antagonistas do marxismo às quais se opõe.

É interessante observar a coincidência: a filosofia oficial da União Soviética, fiel às suas origens stalinistas, considera a "ideologia revolucionária" como um mero derivado da "doutrina científica" do marxismo, o que efetivamente serve para

5 Esse suposto paradoxo está expresso em Mannheim (1972), o que justifica, para o autor, a tarefa da sociologia em indicar como se estruturam as disputas pela ideologia dominante. Mannheim aponta que o marxismo defende uma visão restrita de ideologia, de acusação da vinculação social das ideias. E caberia à sociologia do conhecimento explicar a ligação das ideias à materialidade dos fatos. 
legitimar a manipulação política e ideológica das massas; o althusserianismo, fiel às mesmas premissas teóricas, afirma que a ideologia é o oposto da ciência e só se pode falar em "ideologia revolucionária" como luta da ciência contra as ideologias; o renegado Colletti é contra "todas" as ideologias, inclusive o marxismo; filósofos e epistemólogos burgueses como Popper, Bachelard, Mário Bunge, etc. convergem num ponto básico: a ideologia é considerada como um desagradável resíduo que se refuga nos escaninhos da produção científica. Todos, enfim, se negam a reconhecer na ideologia mais do que um epifenômeno da ciência, seja fazendo sua apologia, como no caso do stalinismo, seja denunciando-a como inimiga do saber objetivo e científico. (GENRO FILHO, 1986, p. 96-97).

A ideologia não estaria somente na classe dominante. Seguindo a definição de Gramsci, Genro Filho cita em alguns trechos de "O Segredo da Pirâmide" o conceito de hegemonia, o que pressupõe a produção para a disputa da prevalência nos processos de ideação. Por outro lado, a ideologia não está em oposição à teoria, pois a teoria e o conhecimento científico também são mobilizados para ações ideológicas. A teoria pode auxiliar nas disputas ideológicas pela própria natureza subjetiva da produção. Porém não cabe exclusivamente a ela mobilizar os sujeitos. A história é farta de exemplos para demonstrar que não foi o conhecimento teórico que mobilizou os participantes da Revolução Francesa, mas situações concretas de conflito no seio social.

A ideologia é um sistema de idéias mais ou menos delineado que implica num compromisso do sujeito diante da totalidade do mundo histórico-social, e não apenas num compromisso epistemológico diante dos objetos reconhecidos em sua positividade. A ideologia implica numa postura ativa da consciência frente à realidade histórica do mundo, envolvendo negação ou afirmação desse mundo de parte do sujeito consciente. Negar a possibilidade da ideologia revolucionária é posicionar-se, ontologicamente, como objeto entre os objetos ou, na melhor das hipóteses, acreditar que a objetividade - por meio da teoria - pode desvelar sua "verdade" independente da postura efetivamente revolucionária do sujeito, a qual exige uma atividade prático-crítica. (GENRO FILHO, 1986, p.97)

Em "O Segredo", essas afirmações encontram uma aplicação, que pode ser sistematizada a partir de três usos da palavra ideologia. Primeiramente, Genro Filho critica aqueles que tomam o jornalismo somente em sua positividade, como um exercício plenamente objetivo no qual o jornalista realizaria a reprodução da realidade sob a orientação da imparcialidade. A palavra ideologia também aparece na análise das teorias marxistas que entendem o jornalismo apenas como uma modalidade da ideologia da classe dominante, como um epifenômeno da disputa de classes. O terceiro uso do termo ideologia em "O Segredo" indica a possibilidade de o jornalismo ser feito com outra ideologia, revolucionária. 
A crítica à ideologia de senso comum da categoria que explica a prática do jornalista pelo viés psicológico e mecanicista da imparcialidade e da objetividade é sobejamente exposta ao longo de todo "O Segredo". Para o autor, essa percepção da notícia como reflexo direto e inconteste da realidade e a defesa da anulação da subjetividade do jornalista frente aos fatos articulam-se a uma compreensão funcionalista para a manutenção da ordem, com relatos que seriam mais equilibrados para garantir a não proliferação de ideologias, caso, por exemplo, do realizado por Rossi (1984, p. 10-12) sobre a necessidade de ouvir os dois lados e não se envolver psicologicamente com as notícias. Para Genro Filho, ao procurar se isentar, os jornalistas reproduzem as ideologias dominantes, impregnadas no senso comum.

Por sua vez, Genro Filho precisa enfrentar o antídoto usado contra essa fórmula da prática: aquelas críticas que entendem o jornalismo exclusivamente como resultado da ideologia da classe dominante. Marcondes Filho (1986, p.13) define que

Notícia é a informação transformada em mercadoria com todos os seus apelos estéticos, emocionais e sensacionais; para isso a informação sofre um tratamento que a adapta às normas mercadológicas de generalização, padronização, simplificação e negação do subjetivismo. Além do mais, ela é um meio de manipulação ideológica de grupos de poder social e uma forma de poder político.

Contrapondo esta visão, Genro Filho (1987) argumenta que o jornalismo possui valor de troca, o que possibilita à informação jornalística ser mercadoria. Mas também possui um valor de uso, uma universalidade enquanto atividade imprescindível aos homens e mulheres na contemporaneidade ${ }^{6}$. Ou seja, a teoria vem trazer aspectos desse valor universal do jornalismo, que pode ser mobilizado para particularidades específicas - seja para a ideologia comunista (o que na visão do autor conduziria à liberdade), seja para uma ideologia burguesa. O que significa que a teoria por ele proposta deve ser testada para compreender o jornalismo feito pela burguesia, pois serve como leitura mais acurada de um fenômeno que nasce no cerne do capitalismo, mas transcende a particularidade na qual está inserido.

A partir de tais elementos potencialmente explosivos que atravessam todas as dimensões da produção simbólica de uma práxis socialmente dilacerada é que surge, de um lado, o reconhecimento da ideologia espontânea das classes dominadas e, de outro, a possibilidade de expansão da ideologia revolucionária a partir daquela (GENRO FILHO, 1987, p.59).

Essa definição de ideologia fundamenta a crítica a muitas das teorizações de esquerda dos anos 1980 que consideram o jornalismo exclusivamente como um fenômeno

6 Considerações sobre essa proposição de Genro Filho são feitas por Rüdiger (2010), ainda que este ressalte que a proposta de "O Segredo" carece de criticidade da produção de conhecimento alinhavada aos interesses ideológicos de mercado. Consideração, de certa forma, genérica, pois toda forma de conhecimento é, nas sociedades capitalistas, intimamente vinculada à finalidade mercadológica sem, no entanto, perder sua dimensão de conhecimento. 
ideológico da burguesia. Por outro lado, essa proposição do jornalismo como instrumento da burguesia traz outra decorrente: a de que o jornalismo como ideologia pode servir para a reprodução da ciência marxista como disposta por um partido ou agrupamento de esquerda tal qual um instrumento proletário. O jornalismo não seria uma forma de conhecimento autônoma, mas um epifenômeno da ideologia, uma espécie de espectro que estaria apenas circunscrito à disputa de classes. Com o fim da disputa de classes, acabaria o jornalismo. Essa visão associada ao stalinismo vê o jornalismo apenas como manipulação e possibilidade de legitimação de um tipo de marxismo e não como uma modalidade para conhecer a realidade e atender a uma necessidade social específica (GENRO FILHO, 1987, p.146-149).

O desbaste dessa posição não está somente na possibilidade de buscar no jornalismo uma conceituação que Ihe permite ascender à categoria de conhecimento. Está nas premissas teóricas do autor, visto que sua definição de ideologia diverge dessas correntes. De uma das premissas, decorre uma primeira consequência para a definição da palavra ideologia presente no livro: o jornalismo pode servir de vetor da ideologia burguesa, ter sua gênese vinculada ao desenvolvimento da burguesia, mas possui atribuições que excedem tais características. Para Genro Filho, não se trata de indicar que o jornalismo não é ou não veicula ideologia, mas de apontar que qualquer forma de conhecimento, de ação humana, agrega-se a posições subjetivas que podem ou não exercer a função ideológica.

Essa concepção de ideologia de Genro Filho é comparável à de Lukács (2013, p.464575). Tomando a explicação gnosiológica como uma fração da definição, Lukács (2013, p.464 e seguintes) defende duas caracterizações para a ideologia, uma ampla e outra restrita. Segundo a primeira, ampla, a ideologia está vinculada à própria possibilidade social dos sujeitos enquanto integrantes do ser social. Tal definição pode ser compreendida ao percebermos que qualquer ação precisa do acúmulo de informações, de táticas que formam um comportamento frente aos demais comportamentos. O próprio desenvolvimento social é condicionado por diferentes determinações dessa definição mais ampla de ideologia.

A segunda definição de ideologia, mais restrita, refere-se às lutas no interior de agrupamentos humanos para atender às respostas ao "que fazer?" mediante conflitos sociais. É nesses conflitos de interesses pelos rumos de diferentes instâncias problemáticas do social que tem origem o significado pejorativo da ideologia (LUKÁCS, 2013, p. 465). É a partir dessa definição restrita, em articulação com a ampla, que podemos depreender um conjunto de consequências para o entendimento ontológico da questão.

Para uma ideia ser ideologia não basta ser produto do pensamento de um sujeito ou de um agrupamento relativamente amplo. Lukács vai determinar que a ideologia passa a existir quando os homens e mulheres aplicam uma ideia, ou complexo de ideais, para se conscientizarem de um conflito e o enfrentarem até (aparentemente ou não) solucioná-lo. "A ideologia é, sobretudo, a forma de elaboração ideal da realidade que serve para tornar a práxis social humana consciente e capaz de agir. Desse modo, surge a necessidade 
de concepções para a resolução dos conflitos do ser social" (LUKÁCS, 2013, p. 465). Sob esse aspecto, qualquer ideia pode vir a se tornar ideologia, ainda que nem todas - relativamente poucas - assumam essa condição. Muitas ideias falsas podem resolver conflitos concretos, assim como verdades científicas podem cumprir essa função. Por exemplo, podemos citar Marx ao indicar que Deus pode não existir, mas, ainda sim, existe nas relações concretas de inúmeros sujeitos. Ou, em outro exemplo, como as descobertas de Darwin alteraram o modo como os sujeitos concebem a si e o mundo a sua volta, transformam um conjunto de práticas, resolvem alguns conflitos e geram muitos outros. Portanto, a ideologia não pode ser oposta ao conhecimento, pois o próprio conhecimento tem a virtualidade de se impor como ideologia.

Verdade e falsidade ainda não fazem de um ponto de vista ideologia. Nem um ponto de vista individualmente verdadeiro ou falso, nem uma hipótese, teoria, etc., científica verdadeira ou falsa constituem em si e por si só uma ideologia: eles podem vir a tornar-se uma ideologia, como vimos. Eles podem se converter em ideologia só depois que tiverem se transformado em veículo teórico ou prático para enfrentar e resolver conflitos sociais, sejam estes de maior ou menor amplitude, determinantes dos destinos do mundo ou episódicos (LUKÁCS, 2013, p.467).

Os conhecimentos cientificamente produzidos não são em si ideológicos. Isso porque não integra seus objetivos resolver conflitos sociais. Porém, os desdobramentos desse conhecimento podem agir como ideologias no campo social (LUKÁCS, 2013, p.467; FORTES, 2012, p.229). E, em muitos casos, tais desdobramentos condicionam a produção desses conhecimentos. Nas Ciências Naturais, mesmo a dimensão subjetiva sendo fundante, a prática tende para a objetividade (GENRO FILHO, 1987, p. 159), com o crescente desenvolvimento do conhecimento sobre as legalidades da natureza para o desempenho mais especializado dos sujeitos com o metabolismo natural (LUKÁCS, 2013, p.562-563; FORTES, 2012, p. 229). Por sua vez, nas ciências sociais, a ideologia possui maior determinação, pois o objeto das ciências sociais são os pores teleológicos secundários, aqueles que têm por objetivo provocar modificações no comportamento e na consciência dos sujeitos.

\footnotetext{
Nas ciências sociais, a questão é objetivamente mais simples, mas subjetivamente ainda mais controvertida. Ela é mais simples porque o fundamento ontológico de toda ciência social é constituído por pores teleológicos que visam provocar modificações na consciência dos homens, em seus futuros pores teleológicos. Só com isso, tanto sua gênese quanto o seu efeito já contêm um elemento irrevogavelmente ideológico (LUKÁCS, 2013, p.563).
}

Genro Filho, mesmo ao criticar Lukács (1970) quanto à categoria do reflexo, expõe o mesmo sentido para a relação das ciências sociais com a ideologia. O que gera consequências para o jornalismo, pois ao expor o fato social na estrutura 
conflitiva que o engendra, o jornalismo oferece caminhos para a tomada de posição diante desses conflitos.

"As ciências sociais, ou humanas, por seu turno, constituem uma revelação da objetividade na qual a subjetividade (ou a ideologia, dito de modo mais específico) que a pressupõe não se manifesta como um resíduo, mas a como uma dimensão intrínseca à teoria e que a constitui como um conteúdo necessário e legítimo" (GENRO FILHO, 1987, p. 159).

Em outro aspecto, mesmo envolvidos na reprodução social de determinados códigos ideológicos, somente alguns sujeitos participam das disputas pelos sentidos em determinado conflito social. Principalmente aqueles que vivenciam diretamente o conflito (episódico ou estruturante), se envolvem e disputam a produção hegemônica sobre ele. São grupos de interesses antagônicos que buscam impor suas motivações à sociedade como se fossem do interesse de todos (LUKÁCS, 2013, p. 471-472). Esse pôr teleológico específico que almeja e às vezes atinge o status de ideologia define-se por um modo de objetivação que se efetiva ao

[...] [1] transformar, pelo menos potencialmente e com muita frequência realmente, as experiências individuais em posse espiritual comum de um grupo humano; [2] ao fazer isso não simplesmente de modo fático, mas proporcionando aos homens modelos - tanto positivos como negativos - para suas decisões futuras, [3] ao converter, tanto no homem singular como nos grupos humanos, a continuidade objetivamente disponível, mas simultaneamente e para além disso, também vivenciada, de suas ideias, de seus sentimentos, de suas ações, etc. em componente dinamicamente mobilizada de sua consciência (LUKÁCS, 2013, p. 486)

Tais considerações oferecem elementos do marxismo conforme as posições de Lukács (2013). Para Lukács, a ciência tem por tarefa evidenciar o que existe e o que é verdadeiro. Por sua vez, a ideologia se manifesta na aplicação concreta de ideações (não importa se falsas ou verdadeiras) para a resolução de conflitos, ou seja, em sua funcionalidade. O marxismo, para Lukács (2013, p. 569-570), é, simultaneamente, ciência e ideologia, método e instrumento da luta de classes. Essas afirmações refutam uma interpretação excessivamente epistemológica do marxismo, sua vulgata determinista, e os críticos da vinculação do fazer ciência a um projeto de transformação social.

Por um lado, está claro que, desde o princípio, o marxismo se concebeu como um instrumento, como órgão para dirimir conflitos do seu tempo, sobretudo o conflito central entre burguesia e proletariado. A última tese sobre Feuerbach referente ao antagonismo (e à unidade) entre interpretar e transformar a realidade [...] mostra com toda nitidez que essa postura existe desde o princípio. Tampouco é necessário contestar que alguma vez ele tivesse tido a intenção de dissimular 
a sua própria gênese histórico-social mediante alguma "atemporalidade" formulada gnosiologicamente. [...] O marxismo, portanto, jamais escondeu sua gênese e função ideológicas: é possível encontrar em seus clássicos frequentes formulações no sentido de que ele justamente seria a ideologia do proletariado. Por outro lado, e simultaneamente, em todas as suas exposições teóricas, históricas e sociocríticas, ele sempre levanta a pretensão da cientificidade; [...] (LUKÁCS, 2013, p. 569-570).

Essas reflexões permitem indicarmos que, mesmo sem ter acesso ao capítulo "O Ideal e a Ideologia" de "Para uma Ontologia do Ser Social II", Genro Filho concebe ideologia da mesma forma que Lukács. Tanto as considerações sobre o marxismo, quanto as sobre o jornalismo são similares. O jornalismo, sob esses aspectos, está disposto como artífice de exposição dos conflitos que emergem no social - significativamente os episódicos, mas não só - e veicula, por isso, as soluções, apaziguamentos e transformações que conseguem avançar para a "ontologia da vida cotidiana". Sob essa posição ontologicamente estratégica para o processo de sociabilidade, esses conflitos ganham dimensão mundial, uma vez que materialmente estão integrados no sistema econômico comum. Sob esse diapasão, o jornalismo assume como mediador social das ideologias (tanto em sentido amplo como em restrito). Como produtor de conhecimento e como mediador de ideologias, o jornalismo é local de disputa de classe e não somente aparelho ideológico da burguesia. Isso, porque o jornalismo pode revelar os antagonismos e chegar à estrutura dos fatos sociais e, nesse aspecto, apontar para ações revolucionárias em todos os segmentos da vida cotidiana.

\begin{abstract}
A ideologia é sempre, em cada sociedade determinada, um conteúdo que atravessa todas as criações da cultura: concepções científicas, filosóficas, estéticas, jurídicas, religiosas, políticas, éticas, além de manifestar-se no senso comum, nas obras de arte, nas leis, na moral, no jornalismo, etc. Esse conteúdo ideológico é contraditório e representa, em suas polarizações extremas, os interesses das classes antagônicas (GENRO FILHO, 1987, p. 87).
\end{abstract}

Em suas críticas às teorias que explicam a ideologia apenas como falsidade e o jornalismo apenas enquanto instrumento de dominação, Genro Filho resgata o trabalho do jornalismo como conhecimento e ideologia. Essa avaliação permite à teoria explicar o jornalismo como forma de conhecimento ainda que realizado com interesse de classe da burguesia, visto que ele pode, em muitos de seus conteúdos, expor aspectos da sociedade e influir nas tomadas de decisão contrárias às formas de exploração que o substancia.

Genro Filho retratou essa circunstância sui generis que coloca o jornalismo em outra posição em relação à ideologia (que não a de oposição à ciência) e que, por outro lado, reforça o propósito em defender o jornalismo como forma de conhecimento. Para ele, é ontológico indicar que todo acontecimento vem dotado de um (ou de vários) sentidos e que tais sentidos sempre oferecem uma "postura ideológica". É tarefa do jornalista manter 
uma abertura de sentido, de tal forma que o fenômeno possa, ao mesmo tempo, revelar o contexto de sua produção e o reconhecimento da contradição que emana do próprio fenômeno e que, por isso, contradiz a gênese de sua produção. Em alguns trechos, Genro Filho partilha da ideia de que a realidade potencializa a evidenciação das contradições frente à ideologia dominante, o que leva o jornalista a enfrentar a estrutura que produziu esse fenômeno como um fato pronto, desconstruindo o que aparentemente é fato para reconstituir as mediações que permitem outras posições sobre o fenômeno, outras formas de constituir o fato.

Essa forma de explicar a ideologia e de estabelecer o relacionamento dela com o jornalismo ratifica a posição de Genro Filho frente a um conjunto de interpretações da obra de Marx. Ainda, constitui um espaço de atuação para o pensamento de esquerda em uma prática intelectual e, portanto, eivada de ideações e ideologias. Sob um aspecto, integra o jornalismo no conjunto de práticas simbólicas que nos permite compreender a sociedade e que possibilita a tomada de posição perante os conflitos. Por outro, especifica o jornalismo, pois, entendendo-o não apenas como uma modalidade de ideologia, mas enquanto forma de conhecimento que pode ser usada ideologicamente, o autor lança para o terreno epistemológico desafios que incorrem na necessidade de conceitos e teorias que o explique. O jornalismo, através da produção de notícias, guarda o potencial de ressignificar os fatos sociais e de apresentar a complexidade das mediações envolvidas em cada um deles. Essa posição ética e de precisão aponta para a evidenciação do trabalho jornalístico como arraigado às disputas sociais. O reconhecimento das disputas ideológicas permite a avaliação das consequências do trabalho jornalístico e a produção de conhecimento vinculado a uma postura de classe. Esse jornalismo, diferente do tradicional, permanece necessário e atual, ainda mais em contextos de crise.

Felipe Simão Pontes é professor do Programa de Pós-Graduação em Jornalismo da UEPG, com pós-doutorado em Jornalismo também pela UEPG. É doutor em Sociologia Política e mestre em Jornalismo pela UFSC. felipe271184@yahoo.com.br

\section{Referências}

ALTHUSSER, Louis. Aparelhos Ideológicos de Estado. Rio de Janeiro: Graal, 1979.

CHASIN, José. Marx: estatuto ontológico e resolução metodológica. São Paulo: Boitempo, 2009.

FORTES, Ronaldo V. As Novas Vias da Ontologia em Gyorgy Lukács: as bases ontológicas do conhecimento. Tese (Doutorado em Filosofia), Programa de Pós-Graduação em Filosofia, Faculdade de Filosofia e Ciências Humanas, Universidade Federal de Minas Gerais, Belo Horizonte, 2011. 
GENRO FILHO, Adelmo. A Ideologia da Marilena Chauí. In: GENRO FILHO, Adelmo. Marxismo, filosofia profana. Porto Alegre: Tchê!,1986.

. O Segredo da Pirâmide: Para uma teoria marxista do jornalismo. Porto Alegre: Tchê!, 1987.

GONÇALVES, Elias M. A Dialética do Discurso Jornalístico. Dissertação (Programa de Pós-Graduação em Comunicação). Rio de Janeiro, UFRJ, 1992.

LAGE, Nilson. Ideologia e Técnica da Notícia. Petrópolis: Vozes, 1979.

LUKÁCS, György. Uma Introdução à Estética Marxista. Rio de Janeiro: Civilização Brasileira, 1978.

Para uma Ontologia do Ser Social. São Paulo: Boitempo, 2012.

Para uma Ontologia do Ser Social II. São Paulo: Boitempo, 2013.

MANNHEIM, Karl. Ideologia e Utopia: introdução à sociologia do conhecimento. Rio de Janeiro: Zahar Editores, 1972.

MARCONDES FILHO, Ciro. O Capital da Notícia: o jornalismo como produção social da segunda natureza. São Paulo: Ática, 1986.

MARSHALL, Leandro. Jornalismo na era da publicidade. São Paulo: Summus, 2003.

MARX, Karl; ENGELS, Friedrich. A Ideologia Alemã. São Paulo: Boitempo, 2007.

MEDINA, Cremilda. Notícia: um produto à venda. São Paulo: Summus, 1978.

MEDITSCH, Eduardo. O Conhecimento do Jornalismo. Florianópolis: UFSC, 1992.

MORETZSOHN, Sylvia. Pensando Contra os Fatos. Jornalismo e Cotidiano: do senso comum ao senso crítico. Rio de Janeiro: Revan, 2007.

PARK, Robert E. News as a Form Knowledge: A Chapter in the Sociology of Knowledge. The American Journal of Sociology, v. 45, n. 5, p. 669-686, mar, 1940.

RICOUER, Paul. Ideologia e Utopia. Lisboa: Edições 70, 1991.

ROSSI, Clóvis. O que é o jornalismo? São Paulo, Brasiliense, 1984.

RUDIGER, Francisco. Elementos para a crítica do jornalismo moderno: Conhecimento comum e indústria cultural. Revista Famecos, v. 17, n. 3, p. 216-227, 2010. Disponível em: < http:// revistaseletronicas.pucrs.br/ojs/index.php/revistafamecos/article/download/8189/5878>. Acesso em 16 mar. 2015.

SPONHOLZ, Liriam. Jornalismo, Conhecimento e Realidade: além dos espelhos e das construções. Florianópolis: Insular, 2009.

THOMPSON. John. Ideologia e cultura moderna: teoria social crítica na era dos meios de comunicação de massa. Petrópolis: Vozes, 1995. 